\title{
A PARTICIPATORY APPROACH FOR INVESTMENTS PLANNING
}

\author{
Fabiana Monacciani* \\ Department of Social Sciences \\ University of Naples "L'Orientale" \\ E-mail: fmonacciani@unior.it
}

\begin{abstract}
Aim of the paper is to present a methodology based on Mathematic Programming and Analytic Hierarchy Process to support decision making in defining and assessing the impacts of investments plans, by using a bottom-up participatory approach. The paper shows the application of the proposed methodology to a case study regarding the selection of investments to be included in a regional transport plan.
\end{abstract}

Keywords: stakeholders, participation, investments plans, projects selection

\section{General framework}

In the recent years, huge changes occurred in European and Italian public choice processes, as new governance models have been introduced in order to involve citizens and different actors in decision making procedures regarding local development and integrated public polic ies. Participatory approach, in fact, in nowadays seen as one of the main keys for achieving broad policy objectives, as evidence proves that the real needs of policies beneficiaries can be correctly identified only if the local situation is analyzed as it is perceived by the different groups of stakeholders (European Union, 2009).

Relations and interactions with public policies stakeholders may take place in different ways, ranging from formal assemblies (public meetings, workshops, bilateral consultations) to informal meetings (working groups), have different decis ional power (partnership assemblies, focus groups ) and, therefore, have different capacity of stimulating creativity and collective intelligence (Goldman and Abbott, 2004). Nowadays, a wide range of participatory methods is in use, many drawn from third world development contexts and adapted to new needs and settings. These have been categorized by Pretty and Vodouhe (1998) into four main classes: 1) group and team dynamics; 2) sampling ; 3) interviewing and dia logue; 4) visualization and diagramming. Bobbio (2004), in its handbook on inclusive decision-making processes describes more than twenty instruments, among which the most well-known are: the GOPP method (Rosenberg and Posner, 1979), recognized by UE (2009) as the "quality standard" for programming, managing and assessing complex interventions, the Metaplan technique, the OST technique, the EASW and the Appreciative Inquiry.

Even though today much stress is given to participation as the key factor for successful public planning, practical evidence shows that, at least in Italy, stakeholders involvement has a very low profile because stakeholders have only consultative power, and the stage for expressing stakeholders perceptions comes only at the end of decision making process, instead of following each decisional phase; in particular, the first phase of such process, during which preliminary choices, highly affecting the final decision, regarding alternatives, weights, criteria, and constraints are set, are almost completely managed by politicians and techniques without involving other social stakeholders.

On the contrary, we think that the preliminary phase is the one where social actors should be actively involved, as this is the phase where the destiny of local development is inevitably defined.

\footnotetext{
* Corresponding author
} 
With reference to such issue, aim of the paper is to present a participatory methodology, based on mathematic programming and Analytic Hierarchy Process, helping to structure public policy by using a bottom-up approach. The advantages of such model are that it helps decision making both in defining the features of alternatives to focus on during following phases, and in choosing, among them, which is the best one to implement in order to better achieve policy goals.

In particular, the proposed approach aims at supporting the decisions related to the definition and assessment of investments programs. Such topic is very important because, since late nineties, public investments planning has been characterized by a deep attention towards integration, seen as one of the key features to make public action more incisive and more efficient in reaching important targets; for these reasons, today, problems related to the difficulty of designing investments programs are some of the most discussed subjects in many public forums. A correct and efficient integrated planning, in fact, must take into consideration both huge quantities of intersectoral project proposals, and a variety of different stakeholders whose targets are often very different from those of others; despite such difficulties, the final result of decision making process must be the identification of the best investments set to be included in medium-long term plans, whose conjoint implementation allows to reach the best compromise impacts on multilevel and multi-actor relevant targets.

Therefore, no judgment about investments ranking is needed, while investment selection is required.

\section{Methodological description}

Investments planning is a typical multi-objective, multidimensional and multilevel decisional problem, and it needs to be treated by adequate multicriteria DSS, based on effective computation models. In order to support such decis ional problem, in a participatory way, we propose the following two step procedure: the first phase aims at identifying, for each group of stakeholders, which is the best compromise investments mix to be included in the plan. Such step is supported by the use of linear mathematic optimization models with binary variables, whose formulations are defined by the interaction of each group of stakeholders with the analyst. The interactive process ends when each group of stakeholders is satisfied by the impacts generated by the selected investment mix;

the second phase, instead, aims at choosing the preferred solution among those previously found by each group. Such step is supported by AHP methodologies, where pair wise judgments among objectives are calculated as the weighted mean of each stakeholder's judgment, while comparisons between alternatives, with reference to each goal, are set by the analyst.

The approach used in phase one is inspired by the fundamentals of Goal Programming (Charnes and Cooper, 1961; Lee, 1972). Such approach requires that each group of stakeholders solves the following mathematic model:

$$
\begin{array}{ll}
\max & d(\mathbf{x})=\sum_{q} w_{q} d_{q} \\
\text { S.T. } \quad \sum_{q} c_{j q} x_{j} \geq \underset{=q}{S} & \\
\sum_{q} c_{j q} x_{j} \geq \underline{T}=q n \\
x_{j}\left(1-x_{j}\right)=0 \\
\sum_{q} w_{q}=1 \\
w_{q} \geq 0 \\
q=1, \ldots, Q ; \quad j=1, \ldots, J ; n=1, \ldots ., N
\end{array}
$$

where:

with:

$$
d_{q}=\frac{\left|\mathrm{O}_{q}^{*}(\mathbf{x})-\mathrm{O}_{q}(\mathbf{x})\right|}{\mathrm{O}_{q}^{*}(\mathbf{x})}
$$

$\mathrm{O}_{q}$ as the generic plan target; 
$\mathrm{O}_{q}^{*}$ as the ideal value of each target, calculated by taking into consideration only exogenous constraints ${ }^{1}$; $x_{j}$ as the generic project to be included in the plan;

$c_{j q}$ as the impact of each project $j$ on each target $q$;

$T_{q n}$ as the discretional value, fixed by each $n$ group of stakeholders, that should be reached by target $q$;

$S_{q}$ as the exogenous value that should be reached by target $q$;

$w_{q n}$ as the weight associated to target $q$ by each $n$ group of stakeholders;

In particular: a) parameters $\mathrm{O}_{q}, x_{j}, c_{j q}, S_{q}$ are defined by technical staff, together with political decision maker; b) parameters $T_{q n}$ are discretionally set by each group of stakeholders thanks to interactive procedures with the analyst bringing to the construction of different evaluation scenarios; c) vector $w_{q n}$ is obtained by calculating the mean value of the vectors of each individual belonging to the $n$ group, determined by using AHP procedures of pair wise comparisons.

Differences in $T_{q n}$ and $w_{q n}$ parameters among different groups, therefore, determine different final solutions for each, that is to say the best compromise investments mixes to be included in the plan, according to different preferences and thresholds expressed by the various stakeholders.

Such solutions represent the first, main contribution that each group offers to the preliminary phase of decisional process.

After determining the features of different plan configurations to be further assessed, next step consists in choosing the best one to actually implement.

This phase may be carried out by using AHP to determine the global weight of each "investments pack" in relation to the different plan targets priorities previously identified by stakeholders. In particular, local weights of targets can be calculated as the mean value of $w_{q}$ vectors generated by each group of stakeholders during the preliminary phase, while local weights of alternatives may be defined by the analyst, whose task is to technically judge their performances with reference to each target.

\section{Application and results}

The proposed participatory method for investments planning has been experimentally tested as a decision support system for assessing and selecting road investments to be included in Abruzzo Regional Integrated Transports Plan (PRIT).

Stakeholders involved in such test, 15 in total, have been divided into four groups: collective representatives (Transports Alderman, Regional Council, Presidents of Abruzzo Provinces), economic operators (touristic operator, public transports operator, logistic operator), parks representatives (Abruzzo National Park, Maiella Regional Park and Silente National Park) and residing civil society (student, employee, pensioner). Road investments proposals to be included in PRIT derived from preexisting projects, but also from new suggestions derived by PRIT technical staff and by various stakeholders at different levels. In total, 26 project proposals have been assessed and compared, in order to skim some of them because of financial and technical constraints.

The projects to be included in PRIT have been evaluated with reference to 20 targets, measured through 20 evaluation criteria; by the way, to simplify information and participatory procedures, original criteria have been aggregated into 7 synthetic indicators (tab. 1), by normalizing original values and, then, calculating the average. Such operation has been done to simplify stakeholders understanding, reduce the number of pair wise comparisons and, therefore, increase consistency.

With reference to such aggregated criteria, each stakeholder has been asked to make pair wise comparisons and to express their preferences by using Saaty scale (Saaty, 1980).

Survey results are summarized in table 2 showing the mean weight vector for each group and the related consistency index; standard deviations and variability coefficients ${ }^{2}$, calculated with reference to each group (tab 3), show that for people belonging to the same group there is a modest homogeneity in preferences, at least in terms of ordinal scale.

\footnotetext{
${ }^{1}$ Such value is calculated by the analyst during a "technical step", before interaction with stakeholders

${ }^{2}$ Variability coefficient is calculated as the ratio between the standard deviation and the mean value.
} 
Tab 1 - Original and aggregated criteria

\begin{tabular}{|l|l|}
\hline \multicolumn{1}{|c|}{ INITIAL CRITERIA } & \multicolumn{1}{|c|}{ AGGREGATED CRITERIA } \\
\hline 1) Total investment cost $(€)$ & 1) Financial values \\
2) Annual management cost $(€)$ & 1) Financial values \\
\hline 3) Mileage redution on road net (equivalent vehicles* Km) & 2) Effects on road net decongestion \\
4) Reduction of time spent on road net (equivalent vehicles*h) & 2) Effects on road net decongestion \\
5) Reduction of congested road (Km) & 2) Effects on road net decongestion \\
6) Offloading of coastal roads & 2) Effects on road net decongestion \\
\hline 7) Fuel consumption (lt/vehicle) & 3) Travel costs \\
8) Travel time (h) & 3) Travel costs \\
\hline 9) NPV direct benefits ( $€$ ) & 4) Economic performance \\
10) Present direct benefits/costs & 4) Economic performance \\
\hline 11) Coherence with National Programs (scale 1-5) & 5) Coherence with current programming \\
12) Coherence with Regional Programs (scale 1-5) & 5) Coherence with current programming \\
13) Coherence with Provincial Programs (scale 1-5) & 5) Coherence with current programming \\
14) Coherence with PRIT Program (scale 1-5) & 5) Coherence with current programming \\
\hline 15) Accessibility of internal areas (scale 1-5) & 6) Accessibility \\
15) Accessibility of industrial and tertiary infrastructures (scale & 6) Accessibility \\
17) Accessibility of touristic areas (scale 1-5) & 6) Accessibility \\
18) Accessibility of cities (scale 1-5) & 6) Accessibility \\
\hline 19) Environmental impacts on protected areas (scale 1-5) & 7) Environment and health \\
20) Impacts on public health (scale 1-5) & 7) Environment and health \\
\hline
\end{tabular}

Tab 2 - Weight vectors for each group

\begin{tabular}{|c|c|c|c|c|}
\hline \multirow{3}{*}{ Targets } & \multicolumn{4}{|c|}{ Stakeholders groups } \\
\hline & Group 1 & Group 2 & Group 3 & Group 4 \\
\hline & Collective representatives & Parks representatives & Residing civil society & Economic operators \\
\hline 1) Financial values & 0,215 & 0,064 & 0,113 & 0,091 \\
\hline 2) Effects on road net decongestion & 0,148 & 0,091 & 0,245 & 0,230 \\
\hline 3) Travel costs & 0,159 & 0,075 & 0,211 & 0,312 \\
\hline 4) Economic performance & 0,122 & 0,188 & 0,075 & 0,054 \\
\hline 5) Coherence with current programming & 0,138 & 0,041 & 0,055 & 0,031 \\
\hline 6) Accessibility & 0,115 & 0,221 & 0,233 & 0,231 \\
\hline 7) Environment and health & 0,103 & 0,322 & 0,069 & 0,052 \\
\hline Inconsistency & 0,077 & 0,078 & 0,083 & 0,065 \\
\hline
\end{tabular}

Tab 3 - Variability indexes

\begin{tabular}{|c|c|c|c|c|c|c|c|c|}
\hline \multirow{3}{*}{ Targets } & \multicolumn{8}{|c|}{ Stakeholders groups } \\
\hline & \multicolumn{2}{|c|}{ Group 1} & \multicolumn{2}{|c|}{ Group 2} & \multicolumn{2}{|c|}{ Group 3} & \multicolumn{2}{|c|}{ Group 4} \\
\hline & St.dev. & Var. coeff. & St.dev. & Var. coeff. & St.dev. & Var. coeff. & St.dev. & Var. coeff. \\
\hline 1) Financial values & 0,081 & 0,392 & 0,018 & 0,249 & 0,043 & 0,376 & 0,007 & 0,076 \\
\hline 2) Effects on road net decongestion & 0,073 & 0,463 & 0,035 & 0,433 & 0,138 & 0,565 & 0,072 & 0,315 \\
\hline 3) Travel costs & 0,058 & 0,379 & 0,011 & 0,157 & 0,129 & 0,615 & 0,132 & 0,425 \\
\hline 4) Economic performance & 0,090 & 0,626 & 0,021 & 0,118 & 0,036 & 0,476 & 0,004 & 0,067 \\
\hline 5) Coherence with current programming & 0,069 & 0,529 & 0,008 & 0,173 & 0,040 & 0,734 & 0,003 & 0,080 \\
\hline 6) Accessibility & 0,057 & 0,500 & 0,014 & 0,062 & 0,200 & 0,858 & 0,201 & 0,871 \\
\hline 7) Environment and health & 0,058 & 0,628 & 0,053 & 0,157 & 0,009 & 0,126 & 0,007 & 0,135 \\
\hline
\end{tabular}

In addition to pair wise comparisons between objectives, stakeholders have been asked to interactively decide the minimum/maximum accepted values of $\mathrm{T}_{\mathrm{q}}$, in order to define the set of discretional constraints that are necessary for calculating the group best compromise solution (tab 4).

Table $4-T_{q}$ set for each group of stakeholders

\begin{tabular}{|c|c|c|c|c|}
\hline & Group 1 & Group 2 & Group 3 & Group 4 \\
\hline $\begin{array}{l}\text { Total investment cost }(* 1000) \\
\text { Offloading of coastal roads }\end{array}$ & $<=4.705 .944$ & $<=4.705 .944$ & $\begin{array}{c}<=4.705 .944 \\
>=3,5\end{array}$ & $<=4.705 .944$ \\
\hline $\begin{array}{l}\text { Fuel consumption } \\
\text { Travel time }\end{array}$ & $\begin{array}{l}<=30 \\
<=4\end{array}$ & & $\begin{array}{l}<=20 \\
<=4\end{array}$ & $\begin{array}{l}<=13 \\
<=1,5\end{array}$ \\
\hline NPV direct benefits $(* 1000)$ & $>=30.000 .000$ & $>=30.000 .000$ & & \\
\hline $\begin{array}{l}\text { Acc. of internal areas } \\
\text { Acc. industrial/tertiary infrastr. } \\
\text { Acc. of touristic areas } \\
\text { Acc. of cities }\end{array}$ & & $>=4$ & $\begin{array}{l}>=4 \\
>=3,8\end{array}$ & $\begin{array}{l}>=3,4 \\
>=4\end{array}$ \\
\hline $\begin{array}{l}\text { Env.impacts on protected areas } \\
\text { Impacts on public health }\end{array}$ & & $\begin{array}{c}>=2,7 \\
>=4\end{array}$ & & \\
\hline
\end{tabular}


Once all the relevant model parameters (exogenous - set by the analyst and by the decision maker - and discretional - set by the group) have been defined, analyst can finally calculate the results for each group, thus obtaining the group best compromise shape of investments plan.

Table 5 shows the selected investments mix by each interviewed group of stakeholders, and the related impacts of such selections.

Table $4 \mathrm{a}-$ Best compromise plans

\begin{tabular}{|c|c|c|c|c|c|}
\hline $\begin{array}{c}\text { Road } \\
\text { Projects }\end{array}$ & Group 1 & Group 2 & Group 3 & Group 4 & $\begin{array}{c}\text { Total } \\
\text { occurrence }\end{array}$ \\
\hline $\mathrm{X}_{1}$ & & & & & $\mathbf{0}$ \\
\hline $\mathrm{X}_{2}$ & & & & & $\mathbf{0}$ \\
\hline $\mathrm{X}_{3}$ & & 1 & & & $\mathbf{1}$ \\
\hline $\mathrm{X}_{4}$ & & 1 & & 1 & $\mathbf{2}$ \\
\hline $\mathrm{X}_{5}$ & 1 & 1 & 1 & & $\mathbf{3}$ \\
\hline $\mathrm{X}_{6}$ & & 1 & & & $\mathbf{1}$ \\
\hline $\mathrm{X}_{7}$ & & & & & $\mathbf{0}$ \\
\hline $\mathrm{X}_{8}$ & 1 & 1 & 1 & 1 & $\mathbf{4}$ \\
\hline $\mathrm{X}_{9}$ & & & & & $\mathbf{0}$ \\
\hline $\mathrm{X}_{10}$ & & & & & $\mathbf{0}$ \\
\hline $\mathrm{X}_{11}$ & & & & & $\mathbf{0}$ \\
\hline $\mathrm{X}_{12}$ & & 1 & & & $\mathbf{1}$ \\
\hline $\mathrm{X}_{13}$ & 1 & 1 & 1 & 1 & $\mathbf{4}$ \\
\hline $\mathrm{X}_{14}$ & 1 & & 1 & & $\mathbf{2}$ \\
\hline $\mathrm{X}_{15}$ & & & & & $\mathbf{0}$ \\
\hline $\mathrm{X}_{16}$ & 1 & 1 & 1 & 1 & $\mathbf{4}$ \\
\hline $\mathrm{X}_{17}$ & & & & & $\mathbf{0}$ \\
\hline $\mathrm{X}_{18}$ & 1 & & & & $\mathbf{1}$ \\
\hline $\mathrm{X}_{19}$ & & & & & $\mathbf{0}$ \\
\hline $\mathrm{X}_{20}$ & 1 & 1 & 1 & & $\mathbf{3}$ \\
\hline $\mathrm{X}_{21}$ & 1 & 1 & 1 & 1 & $\mathbf{4}$ \\
\hline $\mathrm{X}_{22}$ & & 1 & & & $\mathbf{1}$ \\
\hline $\mathrm{X}_{23}$ & 1 & 1 & 1 & & $\mathbf{3}$ \\
\hline $\mathrm{X}_{24}$ & & 1 & & & $\mathbf{1}$ \\
\hline $\mathrm{X}_{25}$ & 1 & 1 & 1 & & $\mathbf{3}$ \\
\hline $\mathrm{X}_{26}$ & & & & & $\mathbf{0}$ \\
\hline Total $_{2}$ & $\mathbf{1 0}$ & $\mathbf{1 4}$ & $\mathbf{9}$ & $\mathbf{5}$ & \\
\hline & & & & & \\
\hline
\end{tabular}

Table 4b Best compromise plans impacts

\begin{tabular}{|l|c|c|c|c|}
\cline { 2 - 5 } & Group 1 & Group 2 & Group 3 & Group 4 \\
\hline Total investment cost (*1000) & 1.928 .056 & 4.583 .205 & 1.765 .610 & 1.244 .456 \\
Annual manag. cost (*1000) & 38.561 & 91.664 & 35.312 & 24.889 \\
\hline Mileage redution on road net & -49.061 & -145.787 & -53.694 & -20.537 \\
Red. of time spent on road net & -3.404 & -10.627 & -3.196 & -2.442 \\
Red. of congested road & $-64,49$ & $-305,47$ & $-70,23$ & $-77,99$ \\
Offloading of coastal roads & 3,77 & 3,88 & 3,75 & 4,18 \\
\hline Fuel consumption & 22,56 & 49,34 & 19,16 & 11,12 \\
Travel time & 3,06 & 6,69 & 2,62 & 1,43 \\
\hline NPV direct benefits (*1000) & 32.762 .285 & 65.031 .218 & 25.823 .645 & 19.533 .145 \\
Present direct benefits/costs & 191,18 & 227,02 & 147,52 & 99,72 \\
\hline Coherence with National Pr. & 4,09 & 4,28 & 4,10 & 4,44 \\
Coherence with Regional Pr. & 3,47 & 3,42 & 3,52 & 3,23 \\
Coherence with Provincial Pr. & 3,66 & 4,13 & 3,74 & 3,75 \\
Coherence with PRIT Pr. & 5,00 & 5,00 & 5,00 & 5,00 \\
\hline Acc. of internal areas & 4,10 & 4,06 & 4,17 & 3,82 \\
Acc. industrial/tertiary infrastr. & 4,10 & 3,97 & 4,00 & 4,22 \\
Acc. of touristic areas & 3,38 & 3,72 & 3,42 & 3,40 \\
Acc. of cities & 3,99 & 3,73 & 3,88 & 4,22 \\
\hline Env.impacts on protected areas & 2,35 & 2,73 & 2,46 & 2,80 \\
Impacts on public health & 3,62 & 4,04 & 3,65 & 3,67 \\
\hline
\end{tabular}

Such final decision has been made during the last step of the process, where all information generated by the upper phase have been employed into an AHP model.

At this stage, pair wise comparisons have been limited to alternatives (plan configurations), because targets local weights (tab. 5) have been directly calculated as the mean value of the weight vectors previous ly generated by the four groups of stakeholders ( $\operatorname{tab} 2)$.

Table 5 - Total population weight vector

\begin{tabular}{|l|c|c|c|}
\hline \multicolumn{1}{|c|}{ Targets } & Mean value tot. & \multicolumn{2}{c|}{ Variability } \\
\cline { 3 - 4 } & population & St. dev & Var. coeff. \\
\hline 1) Financial values & 0,121 & 0,066 & 0,548 \\
2) Effects on road net decongestion & 0,178 & 0,072 & 0,404 \\
3) Travel costs & 0,189 & 0,099 & 0,524 \\
4) Economic performance & 0,110 & 0,059 & 0,542 \\
5) Coherence with current programming & 0,066 & 0,049 & 0,736 \\
6) Accessibility & 0,200 & 0,057 & 0,284 \\
7) Environment and health & 0,136 & 0,125 & 0,920 \\
\hline
\end{tabular}

The task of comparing alternatives with reference to plan targets has been left to the analyst because, at this stage, evaluation is confined to technical aspects, characterized by a low degree of subjectivity.

Table 6 shows the resulting set of local weights for each investments plan alternative.

The last step consists in hierarchy re-composition and, thus, in alternatives global weights calculation. 
Table 6 shows that the found best compromise plan configuration is the one proposed by the fourth group of stakeholders (global weight $=0,66$ ).

Tab 6 - Alternatives local and global weights

\begin{tabular}{|l|c|c|c|c|}
\cline { 2 - 5 } \multicolumn{1}{c|}{} & Group 1 & Group 2 & Group 3 & Group 4 \\
\hline 1) Financial values & 0,277 & 0,181 & 0,201 & 0,341 \\
2) Effects on road net decongestion & 0,153 & 0,403 & 0,303 & 0,141 \\
3) Travel costs & 0,178 & 0,202 & 0,221 & 0,399 \\
4) Economic performance & 0,208 & 0,499 & 0,187 & 0,106 \\
5) Coherence with current programming & 0,217 & 0,288 & 0,204 & 0,291 \\
6) Accessibility & 0,237 & 0,255 & 0,397 & 0,111 \\
7) Environment and health & 0,099 & 0,327 & 0,238 & 0,336 \\
\hline Alternatives global weights & $\mathbf{0 , 5 5 6 7}$ & $\mathbf{0 , 5 8 1 1}$ & $\mathbf{0 , 5 6 3 4}$ & $\mathbf{0 , 6 6 1 2}$ \\
\hline
\end{tabular}

\section{Conclusions}

Implementation of communication and consultation systems among analysts, planners, decision makers and stakeholders directly involved in decisional process is considered today as a key feature for successful public action. According to us, taking into consideration stakeholders judgment since the preliminary phase of decisional process is necessary to improve the quality of public planning; such involvement, in fact, should at least bring contributions to the definition of alternatives and weights. Many failures of public action, in fact, have been caused by the opposition of stakeholders, whose point of view had not been considered during decision making.

To avoid this, participatory approaches should not only provide information (about targets, costs, time schedule etc.) to citizens, but also produce new information and catalyze its exchange among involved social groups. For these reasons, we think that aim of participation should be that of widening informative database, and to make it available for correctly supporting assessment and final decision.

We think that the participatory approach tested for Abruzzo PRIT is an efficient and effective answer to all such questions. In addition, the proposed approach results to be simply applicable, too, as it is not too much time consuming and not very expensive and, therefore, is compatible with resources and timing available during preliminary programming.

\section{REFERENCES}

Bobbio L. (2004), A più voci. Amministrazioni pubbliche, imprese, associazioni e cittadini nei processi decisionali inclusivi, Cantieri - Analisi e strumenti per l'innovazione, Edizioni Scientifiche Italiane, Napoli.

Pretty J., Vodouhê S.D., (1998), Using rapid or participatory rural appraisal, in Swanson B.E., Bentz R.P., Sofranko A.J.(Eds), Improving Agricultural Extension: A Reference Manual, Food and Agriculture Organisation, United Nations.

European Union (2009), EVALSED - Evaluating Socio Economic Development, SOURCEBOOK 2: Methods \& Techniques.

Goldman I., Abbott J.(2004), Decentralisation and community-based planning, International Institute for Environment and Development, London.

Charnes A., Cooper W. (1961), Management models and industrial applications of linear programming, Wiley, New York 


\section{F.Monacciani}

Lee S.M.(1972,) Goal programming for decision analysis, Auerback, Philadelphia

Saaty T. L., (1980), The Analytic Hierarchy Process, McGraw-Hill, New York 